Vol. 5, No. 2, 2018

https://doi.org/10.23939/eem2018.02.039

UDC 658.011:657.62

Z. Skybinska

$\mathrm{PhD}$ in Economics, Associate Professor

T. Gryniv

$\mathrm{PhD}$ in Economics, Associate Professor

Lviv Politechnic National University

\title{
TYPES OF ECONOMIC ANALYSIS AND ITS INFORMATION MAINTENANCE
}

\begin{abstract}
Investigated the types of economic analysis. Described the major tasks internal and external economic analysis. Carried out comparative characteristic of types of economic analysis by the time of making managerial decisions. Investigated specifics into branch and among branch economic analysis. Particular attention is paid to factor analysis.
\end{abstract}

Key words: economic analysis, types of economic analysis, factor analysis.

\section{Introduction}

Type of economic analysis - is an ordered set of elements, concepts, teaching methods and approaches to the study of economic phenomena and processes that are typical for economic analysis as a science, as well as specific properties that are inherent only to this totality. With the formation of the modern classification of economic analysis take into account the requirements of a functional approach (the assessment of customer needs in analysis' results and obtained opportunities from conducting the relevant type of analysis); the need to unify information support of analysis; experience of other countries and so on. In practice, the types of economic analysis are used simultaneously. At each level of management daily take various decisions, to substantiate them use appropriate types of economic analysis. Classification of household analysis has an important value for the correct understanding of its essence and tasks, for development of method of its conducting and for organization of analytical process.

\section{Internal and external economic analysis}

Analysis distribution into internal (managerial) and external is caused by character of information sources, executors and objectives, which seek to achieve during the research. In practice, these types of analytical work often overlap.

The internal analysis is performed directly at the company for the purpose of rapid, short-term and long-term management of industrial, commercial and financial activities. Its results are a strictly commercial.

Purpose of the internal analysis is to promote the supply of internal users by information which is necessary for making grounded management decisions. And the internal users of different levels of management are enterprise's administration, workers of functional divisions and subdivisions and others.

The subjects of internal analysis are workers of functional divisions and subdivisions, special analytical services of the company, accounting firms, consultants and objects are the company and its structural divisions.

As information base of analysis use the full range of economic information including unregulated information. Its content is caused by the organization of accounting process at the enterprise, its technical supply, analyticity, operative credentials. Information should be detailed and confidential.

The main tasks of internal analysis are represented on Fig. 1.

Internal analysis includes retrospective, operational and perspective analysis. In the result of operational and prospective analysis there is a probability of obtaining insufficient reliable output analytical information. Frequency of providing 
analytical information conditioned to the interests of information users (daily, weekly, each decade, etc.). The company can develop methods of analysis by themselves.

So, features of internal analysis are:

- focus on the company's management;

- use of all information sources;

- absence of external regulation of methods of analysis;

- the complexity of analysis, the study of all aspects of the enterprise activity;

- maximum secrecy of analysis' results to preserve commercial secret.

Internal analysis is divided into managerial and financial (Fig. 2).

External analysis is carried out on the basis of financial and statistical reporting by economic bodies, banks and financial authorities, shareholders, investors. It promotes the supply of external users of information with necessary one for selecting the most appropriate line of conduct. External users are real and potential creditors, owners, suppliers, customers, owners of assets of the company, investors, statistics, government agencies, research institutions, regulatory authorities, financial and credit institutions.

The subjects of analysis are external users of analytical information (accounting firms, consultants) and the objects of analysis - the enterprise as a whole. Information base of analysis - financial statements (balance sheet, income statement, cash flow statement, statement of shareholders' equity, notes to the financial statements - regulated information).

The main tasks of external analysis are represented on Fig. 3.

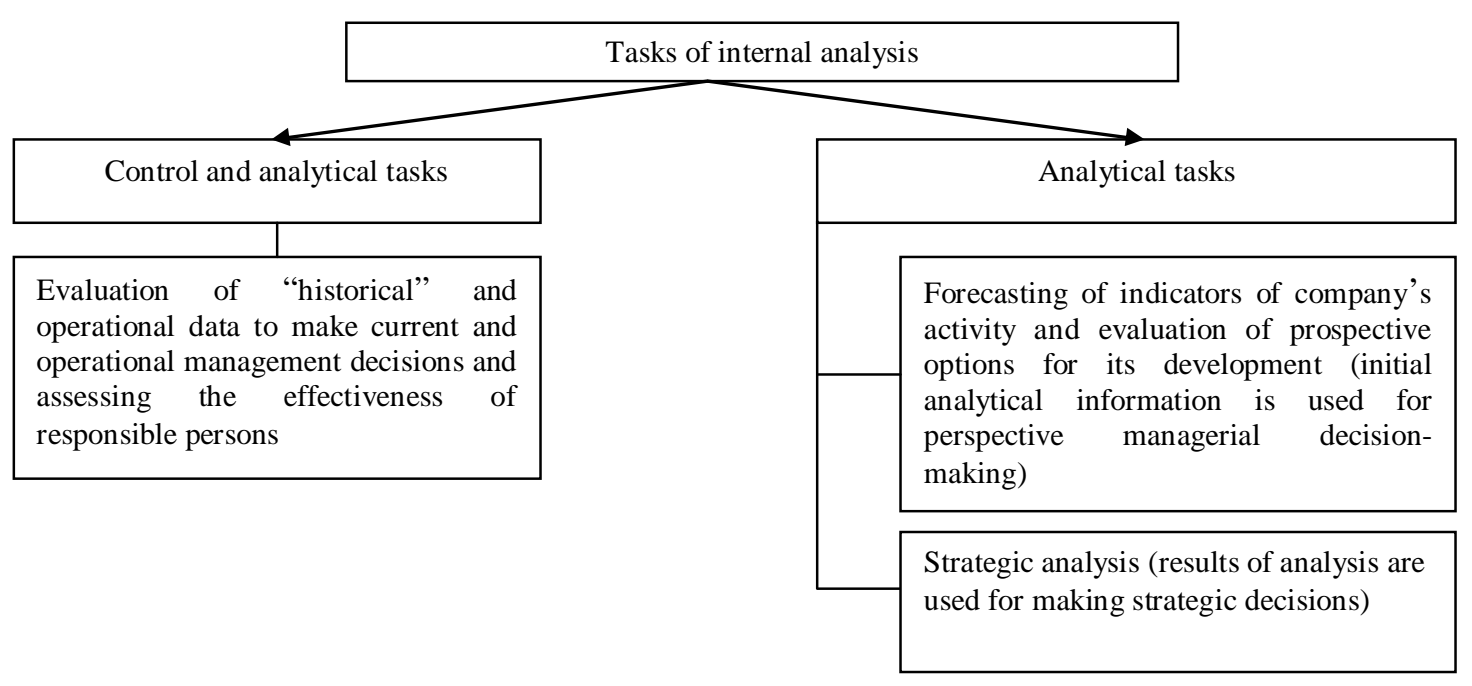

Fig. 1. Tasks of internal analysis

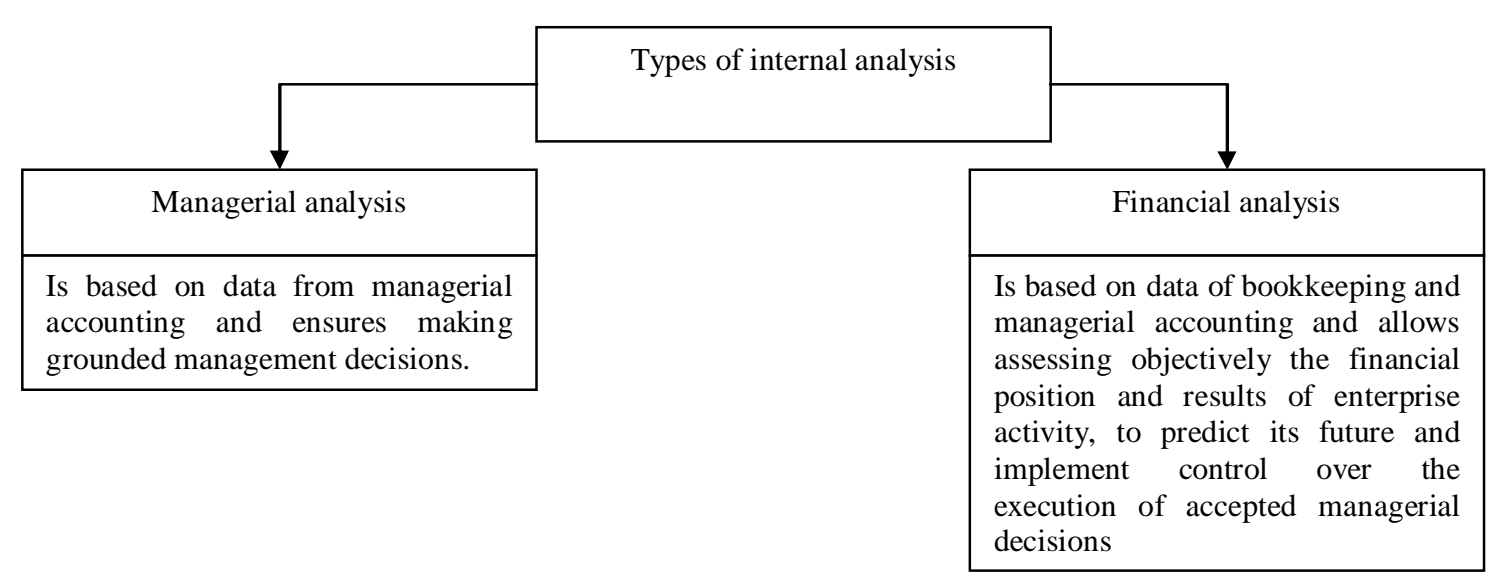

Fig. 2. Types of internal analysis 


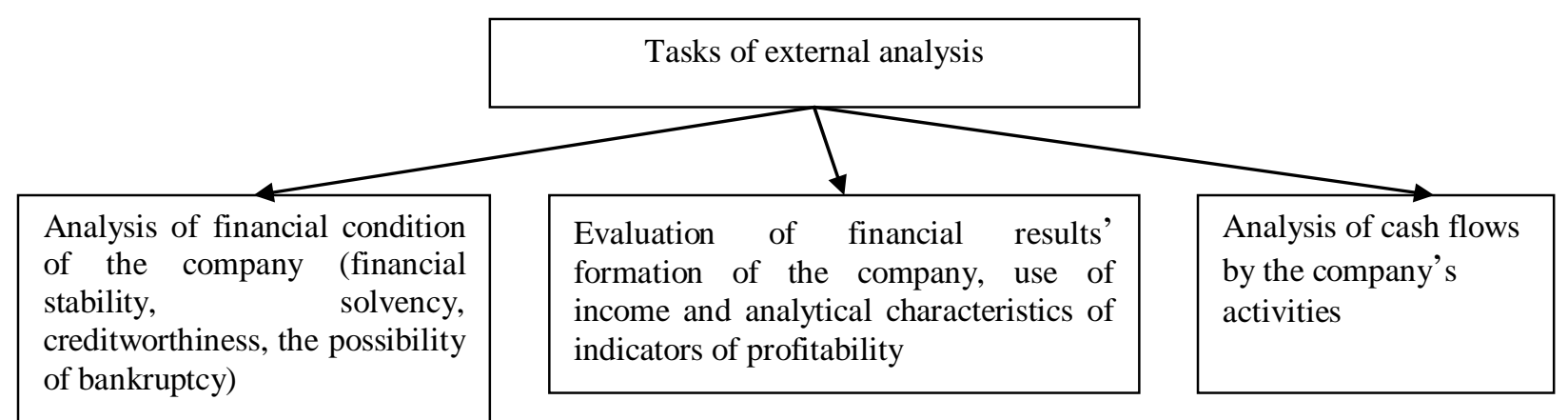

Fig. 3. The tasks of external analysis

Table 1

Comparative characteristics of internal and external economic analysis

\begin{tabular}{|l|l|l|}
\hline \multicolumn{1}{|c|}{ Comparative features } & \multicolumn{1}{|c|}{ Internal economic analysis } & \multicolumn{1}{c|}{ External economic analysis } \\
\hline Objects of research & $\begin{array}{l}\text { Structural subdivisions, economic } \\
\text { phenomena and processes, elements } \\
\text { of economic relations }\end{array}$ & $\begin{array}{l}\text { Enterprises in general, inter object } \\
\text { comparison }\end{array}$ \\
\hline Subjects of research & $\begin{array}{l}\text { Managers and specialists of all } \\
\text { structural levels }\end{array}$ & $\begin{array}{l}\text { National, sectoral and territorial economic } \\
\text { institutions, partners and customers }\end{array}$ \\
\hline Time forms & Strategic, operational, retrospective & Strategic, retrospective \\
\hline $\begin{array}{l}\text { Frequency of analysis } \\
\text { Privacy Policy }\end{array}$ & Permanent & $\begin{array}{l}\text { By the standards of analytical process and } \\
\text { at the request of users }\end{array}$ \\
\hline $\begin{array}{l}\text { The degree of analytical } \\
\text { indicators' integration }\end{array}$ & $\begin{array}{l}\text { The totality of general and partial } \\
\text { indicators }\end{array}$ & General indicators \\
\hline
\end{tabular}

The external analysis is retrospective, characterized by a high degree of reliability and probability of the original analytical information. This information is provided to users on a regular basis, in accordance with the terms of preparation of financial statements (quarterly, annually).

External analysis is only financial.

So, the external analysis features are:

- multiplicity of subjects of analysis - users of information about the company;

- a variety of purposes and interests of subjects of analysis;

- availability of typical methods of analysis to all industries;

- focus only on external financial statements;

- limited tasks of analysis as a result of previous factor;

- maximum openness of analysis results to information users about the company.
The comparative characteristics of internal and external economic analysis are presented in Table 1.

\section{Perspective and retrospective economic analysis}

On the feature of time an economic analysis is divided into perspective (previous) and retrospective (following, historical).

The perspective analysis is conducted before household operations take place. It's needed for household decisions and plans-prognoses substantiation, undesirable results prevention. The perspective analysis depending on time duration is divided into short-term and long-term (strategic). The short-term analysis engulfs a period to one year, and long-term - more a year. A short-term prognosis analysis is applied for making of tactical, and long-term - strategic business policy. The long-term analysis is less detailed, than short-term; 
however its role is more significant. If correct strategy of enterprise development is selected, it is easier to make tactical decisions. In the conditions of market competition a long-term (strategic) analysis becomes an integral part of managerial activity.

Perspective analysis - an analysis of business results to determine their potential value in the future. The results of this analysis are used to develop strategic plans and preliminary evaluation of the results of their implementation. The peculiarity of this analysis is explore the possibilities of achieving the desired results.

Perspective analysis aims finding in each process or phenomenon of economic activity the most stable perspective elements which can play a crucial role in the future.

Tasks of perspective analysis are determined by its essence and place in planning and management (Fig. 4).

During plans' compiling forecast analysis serves as the main form of preplanned researches of business economics, during the execution of busi- ness plans - it is a tool for prediction and evaluation of the expected results.

Sequence of carrying of perspective analysis is shown on Fig. 5.

Perspective analysis is conducted in such main directions:

1) Technical equipment, material, labor and financial resources of the company, production and sales;

2) The degree of product quality and customer satisfaction;

3) Perspective evaluation of costs and expected profit, profitability, solvency and financial condition.

The retrospective analysis is carried out after completion of household acts on the basis official of financial and statistical reporting. It is needed for the study of development tendencies, control after operative plans fulfillment, objective evaluation and diagnostics of enterprise's activity results and of the level of enterprises risks.

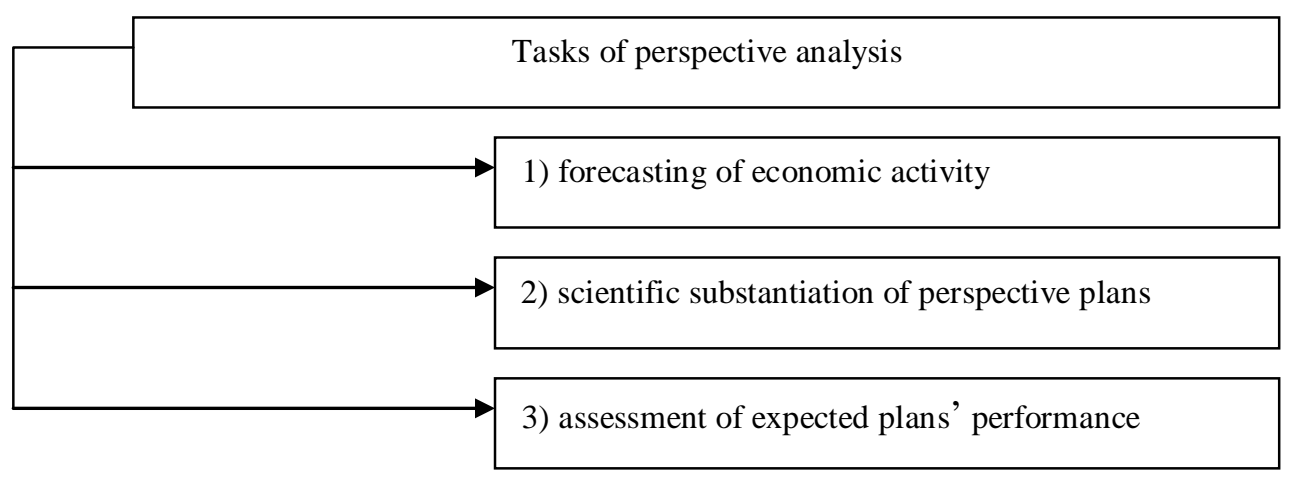

Fig. 4. The tasks of perspective analysis

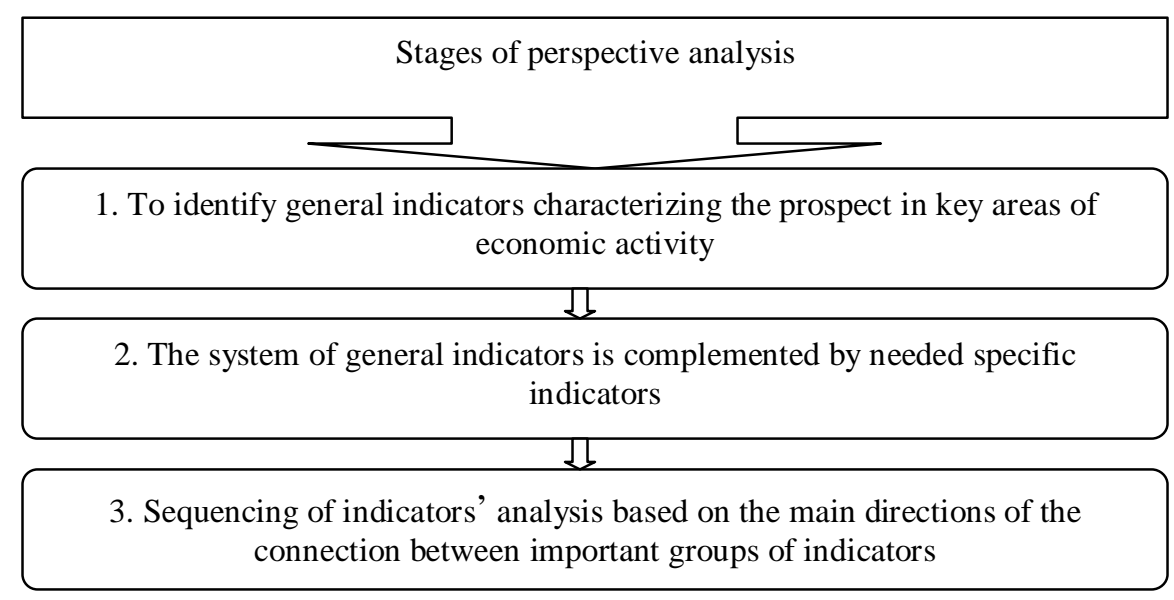

Fig. 5. Sequence of perspective analysis implementation 
The main task of the retrospective analysis an objective assessment of activity results, comprehensive identification of unused reserves and detected drawbacks in the work and responsible executors. The results of retrospective analysis are used to solve problems of strategic management. But this analysis has a significant drawback - identified deficiencies belong to the past periods and mean forever lost opportunities.

Peculiarities of retrospective analysis technique consist in that the actual results of the work are evaluated in comparison with plan and analytical data of the previous periods. Identified in the analysis of deviations from the base of comparison deciphered by technical and economic factors that determine these deviations, shall be established not only the causes of deviations, but the responsible persons, services, are developed measures to eliminate shortcomings in the work.

The retrospective analysis is divided into operative and summary. An operative analysis is conducted right after realization of household operations or change of situation for the short periods of time (shift, day, decade period and so on). Its purpose - operatively estimate changes in relation to the preset parameters, to find out fai- lings and reasons of their appearance, in good time to take correcting measures for their elimination. In respond to the rapid change of all types of enterprise's activity and its environment operative analysis takes on special significance.

Conducting a summary analysis it's necessary to study activity results for the period under review (month, quarter, and year). Its value lays in enterprise activity study in complex and comprehensive way from current data of the proper period. Thus, more complete and more objective estimation of enterprise activity is reached from the use of present possibilities.

Operative and summary analyses are interrelated and complement each other. They enable guidance of enterprise not only operatively liquidate failings in the production process, but also summarize achievements, results of activity for proper periods, to develop measures, directed on growth of business efficiency.

Some scientists by the time of management decision making distinguish analysis perspective, operative and retrospective. If guided by this classification, it is appropriate to compare these types of analysis (Table 2).

Table 2

\section{Comparative characteristics of the types of analysis by the time of management decision making}

\begin{tabular}{|c|c|c|c|}
\hline \multirow{2}{*}{$\begin{array}{l}\text { Comparative } \\
\text { characteristics }\end{array}$} & \multicolumn{3}{|c|}{ Type of economic analysis by the time of management decision making } \\
\hline & perspective & operative & retrospective \\
\hline $\begin{array}{l}\text { According to } \\
\text { the purpose of } \\
\text { analysis }\end{array}$ & $\begin{array}{l}\text { Determination of the } \\
\text { prospects of the company }\end{array}$ & $\begin{array}{l}\text { Evaluation of indicators devia- } \\
\text { tions of the actual situation of the } \\
\text { company from their regulations } \\
\text { and appropriate maneuvering of } \\
\text { resources and capital }\end{array}$ & $\begin{array}{l}\text { Comprehensive diagnostics } \\
\text { and evaluation of the results } \\
\text { of enterprise functioning }\end{array}$ \\
\hline $\begin{array}{l}\text { By the scale of } \\
\text { objects' } \\
\text { research }\end{array}$ & $\begin{array}{l}\text { Parametric general } \\
\text { indicators of the company }\end{array}$ & $\begin{array}{l}\text { Local and general indicators of } \\
\text { operating enterprise activity }\end{array}$ & $\begin{array}{l}\text { The entire set of indicators } \\
\text { of forecasted operating and } \\
\text { summary enterprise activity }\end{array}$ \\
\hline $\begin{array}{l}\text { According to } \\
\text { sources of } \\
\text { information }\end{array}$ & $\begin{array}{l}\text { Legal and regulatory infor- } \\
\text { mation, dynamic series of } \\
\text { indicators of enterprise } \\
\text { activity by generalizing } \\
\text { parameters, target } \\
\text { programs and forecasts }\end{array}$ & $\begin{array}{l}\text { Operative plans, schedules of } \\
\text { operative accounting and } \\
\text { marketing }\end{array}$ & $\begin{array}{l}\text { Current plans and } \\
\text { regulations, accounting and } \\
\text { reporting statistical } \\
\text { information, special surveys } \\
\text { data }\end{array}$ \\
\hline $\begin{array}{l}\text { According to } \\
\text { the terms of } \\
\text { carrying out }\end{array}$ & $\begin{array}{l}\text { Annually, by periods of } \\
\text { planning and forecasting }\end{array}$ & $\begin{array}{l}\text { Daily, by operative periods }(5,10 \\
\text { days, month) }\end{array}$ & Quarterly, annually \\
\hline
\end{tabular}


On the basis of this comparative table and understanding of the classification criteria "time (content of management process)" consider it appropriate to adhere the attribution of operative analysis into the retrospective, since it is being conducted after the business operations took place along with the final one.

Retrospective analysis - the most comprehensive view of economic analysis that incorporates the results operative analysis and is the basis for perspective analysis.

\section{Into branch and among branch economic analysis}

According to the feature of the place of research (particular branch) which is based on the public labor division, an analysis is divided into branch and among branch.

Peculiarities of branch analysis lie in its detailing by separate departments. Branch analysis covers all steps of management hierarchy of basic link of national economy - from the units of the first order to the workplace.

Branch economic analysis consists in objective and comprehensive assessment of reaching target plans by units; identifying and measurement of factors and reasons that have caused production results, revealing branch reserves, development of measures of their use, research of peculiarities of economic functioning and development of one or another unit.

By content branch economic analysis differs significantly from the analysis of the enterprise as a whole. These features are determined by the specific content of economic indicators established by branch division unlike the indicators of enterprise activity as a whole. Often each of the main production departments does not produce fully finished production. Therefore, the main indicators of production efficiency in this case are not profit and profitability but costs of production. In branch analysis use more natural parameters for assessing output, productivity, quality of produced products.

Branch economic analysis has its specific subjects of analysis. If the activities of the company mainly examine the economic life of the enterprise, the higher organization, the economy of branch production units study mainly specialists of the enterprise and the related service divisions.

Significantly different is the InfoBase of branch economic analysis from the information support of analysis of the enterprise as a whole. Branch economic analysis has a wider information base.
For its performance use not only the reporting data, but also consolidated data and even primary documents, because in terms of production units usually group and summarize various primary records about availability and movement of fixed assets; material, labor, production and so on. Consolidated data sources of branch economic analysis include various kinds of workshops' reports on the costs of raw materials and fuel.

An important role in the economic analysis also occupies among branch analysis of enterprises. Its purpose is comparison of results achieved in economic activity with results of other companies or organizations, study the causes of differences in the use of production resources, identifying reserves of further improvement of production efficiency.

Objects of among branch are results of industrial corporations, businesses, industries, workshops, work places. At the same time compared phenomena, processes, objects of the same level (businesses, workshops, products), of one content (labor, equipment, technology, organization), of one dimension (large, medium, small enterprises), of the same parameters and indicators (labor productivity, production capacity, production costs).

Among branch comparisons can be general (full) and partial (local) (Fig. 6).

In general (full) study all the work of enterprises and their units under the general scheme of complex economic analysis. Is implemented by enterprises that produce similar products, ie the enterprises of the same industry or sub-industry.

At the local - study a separate unit or individual single issues (eg., use of power equipment, working time of employees, etc.).

Conducting among branch comparative analysis includes the following stages:

- the choice of enterprises and objects of comparison;

- determination of the degree of comparability and range of comparable indicators;

- gathering and processing of economic information about objects, bringing indicators to comparable type;

- comparison and analysis of indicators, evaluation of achieved results, identification of the causes of differences and the factors that determined the value of the indicator; 


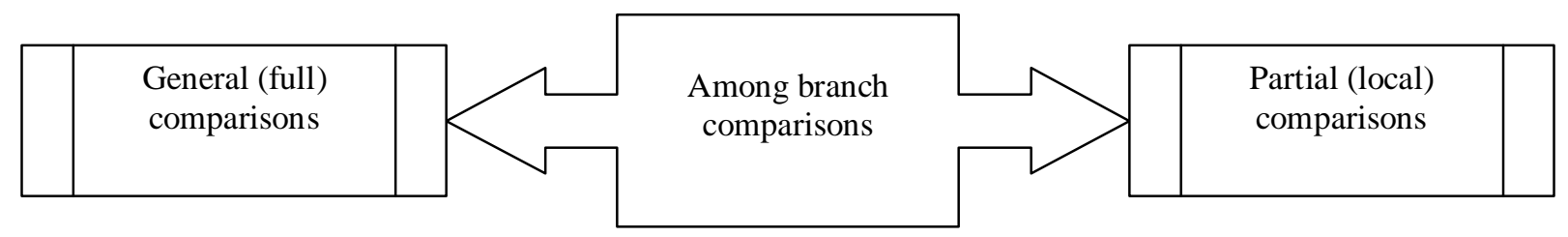

Fig. 6. Types of among branch comparisons

- summarizing the results of the analysis, conclusions and suggestions to improve the efficiency of the comparable objects, the calculation of economic benefits from the implementation of the proposals and the degree of their impact on the general indicators.

At enterprises among branch comparative analysis is performed by chief economist or planning and economic department with the assistance of economic and technical services. Among method of among branch comparative analysis is grouping of enterprises by size, producing similar products. Size of enterprises more fully appear in indicators of volume of production.

Depending on the purpose of analysis is selected base of comparison. In particular, to identify the best enterprise base - a set of indicators, the analysis which will allow comprehensively examine the results of comparable companies, compare them with the results of the leading companies with prior periods.

When choosing of base of comparison to provide comparative indicators (production capacity, energy supply, technical equipment, etc.) and to define indicators which need to be brought to comparative form (productivity, production costs, payroll fund, etc.).

During this analysis appear reasons for the difference of the same indicators, factors which depend and do not depend on the companies in order to increase the objectivity of the terms of comparison.

Most modern achievement in the field of among branch analysis - benchmarking. This early warning system of problems brewing. Benchmarking is used as a tool to obtain the information necessary to achieve and maintain competitive advantages.

\section{The nature of objects' research as a feature of economic analysis classification}

Classification of analysis of business enterprise by dependence on the method of objects research is essential for the developing methods for their implementation. By this feature analysis is divided into:
1) comparative (qualitative);
2) factor (quantitative);
3) diagnostic (express analysis);
4) marginal;
5) economic-mathematical;
6) function-value;
7) fundamental analysis;
8) situation analysis
1) Comparative (qualitative) analysis - a method of research based on qualitative comparative characteristics and expert opinions of phenomena and processes which they study. This analysis is largely limited to a comparison of reporting indicators of business enterprises with planned indicators, reporting data of prior periods, indicators of competitors and more. Application of comparison to economic phenomena gives an opportunity to make a horizontal, vertical, trending, as well as one-dimensional and multidimensional analysis.

2) Factor (quantitative) analysis is based on quantitative comparisons and study of the degree of sensitivity of economic phenomena before changes in various factors. This analysis intended to identify the causes of changes in effective indicators. Types of factor analysis are represented on Fig. 7.

Single-level factor analysis is used to study factors of only one level of subordination without detailing on the components. In the multi-factor analysis factors of the first level are decomposed into components.

Retrospective factor analysis studies the causes of what happened, for instance, why such financial results were achieved; and perspective factors that are considered to be most significant for achievement of the desired results in the future. In practice, these two types are often intertwined, so it is important to organize analysis for making reasonable managerial decisions on certain issues. 


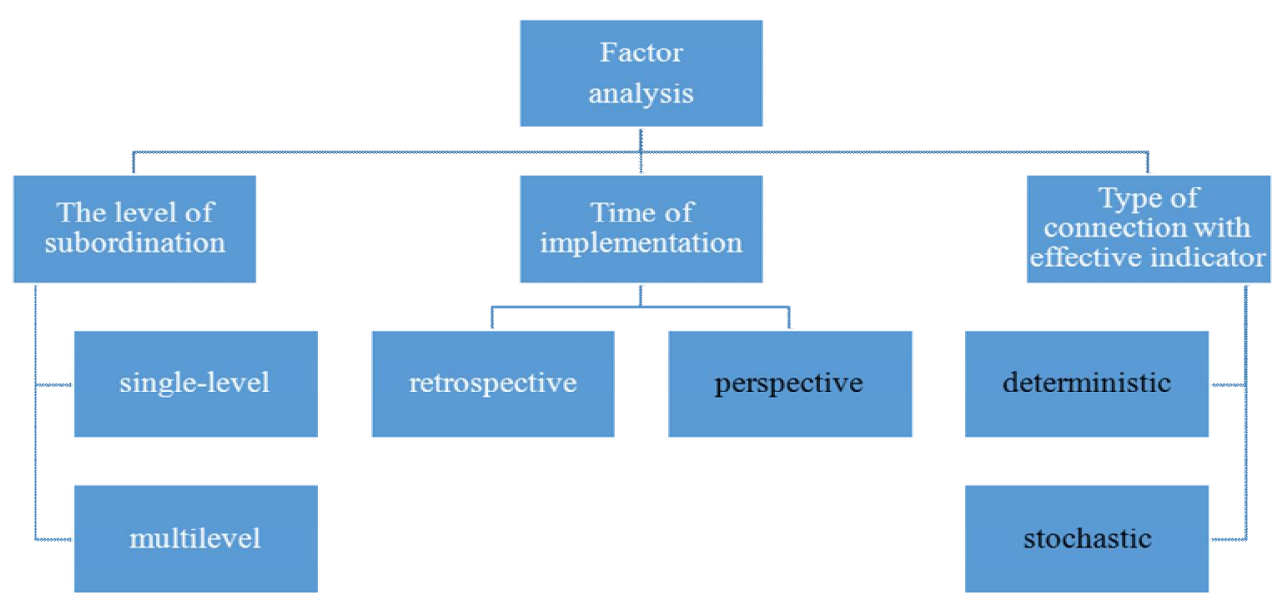

Fig 7. Types of factor analysis

Deterministic factor analysis is used to study the influence of factors which relationship with effective indicator has a functional character. Typical tasks of deterministic analysis include: assessment of the impact of relative changes in factors on relative change of the effective indicator; assessment of the impact of absolute change in certain factors on the absolute change in the effective indicator; determining the ratio of the of changes in the effective indicator caused by the change of certain factor to the base value of the effective indicator; determining the share of absolute change of the effective indicator when changing certain factor. Stochastic analysis explores factors' influence in the connection of which effective indicator is probabilistic (correlation). Such analysis to some extent is a supplement and deepening of deterministic factor analysis. This analysis is used in the following conditions:

- the research of factors' impact for which it is impossible to build a deterministic factor model;

- determination of factors' influence which are not exposed to combining in a single strictly determined model;

- studying of the impact of complex factors which can not be given by one quantitative indicator.

Application of a stochastic approach is possible only with a compulsory precondition that complicates its implementation.

3) Diagnostic analysis - express analysis, a method of enterprise economy state diagnostics on the basis of typical features for the certain economic phenomena, that is the formation of enterprise diagnosis by typical signs. For example, if the rate of gross output growth passes ahead the rate of commodity output growth, it certifies growth of uncompleted production remains. If the rate of commodity output growth is higher than the rate of production sale it is a sign of overstocking. Presence of overdue obligations, deceleration of capital circulating, losses is indicators of probable enterprise bankruptcy. Identification of proper feature enables quickly and accurately determine the nature of violations without taking additional action. For example, express analysis of enterprise covers the following stages: "statements reading"; review the report by their formal attributes; review of accounting policy; identification of "sick" articles in the reporting and evaluation of their dynamics; acquaintance with basic indicators; reading the explanatory notes (analytical sections of the report); overall assessment of financial and property state according to the balance sheet; drawing conclusions from the analysis. Such analysis does not require much time and its implementation - complex calculations and a significant amount of information.

4) Marginal analysis is a method of evaluation and substantiation of managerial decisions efficiency in business on the basis of reason-result interrelation study of sales scope, prime price and profit, as well as division of expenses on fixed and variable. With its help they determine brake-even points of sales, price, fixed and variable expenses, in this case financial result will be equal zero. Optimum production level is in an intersection of total expenses and total revenues. This type of analysis makes it possible to manage a 
profit in business, optimize its parameters depending on deviations in production volume, the share of variable costs, unit prices and more.

5) By economic-mathematical analysis it's possible to choose the most optimum variant of economic task decision, find out backlogs of production efficiency increase due to more complete use of enterprise production potential using complex mathematical tools.

6) Function-value analysis (FVA) is a research of functions which are executed by an object, as well as methods of their realization. Its basic target is to find out the unnecessary functions of object and avoid unnecessary expenses due to liquidation of unnecessary details, simplification of good construction, replacement of materials and so on.

Function-value analysis (FVA) appeared in 40 s of the last century as a result and almost simultaneously in different countries (conducted research of Russian constructor Y. M. Sobolev from Perm telephone factory and American engineer L. D. Mayls of the company General Electric). The first development of Y. M. Sobolev constructed using the results of FVA - node for strengthening mikrotelefone allowed to reduce the number of parts by $70 \%$, the cost of materials by $42 \%$, the labor capacity of production by $69 \%$, and the total cost in 1,7 times.

L. D. Miles in 1946 first formulated the concept of function-value analysis, defining it as "applied philosophy of economic activity, as a system of ways of cost savings before, during and after their implementation". Since then the FVA is considered to be one of the most important innovations in governance over the past hundred years.

The purpose of implementing FVA is to prevent unnecessary production costs by improving production technology and product design, the use of cheaper raw materials.

The essence of the FVA can be briefly described as follows - each type of product produced in the company in order to satisfy the needs of customers, to perform certain functions. Each function has its own feature, since for its creation required materialized labor costs. These functions can be major, minor and generally unnecessary.

Therefore, at the stage of manufacturing products, using FVA, thoroughly study products, detect unnecessary costs, eliminate unnecessary functions of goods and thus decreasing is reached of expenses for production. The basic requirement is that the product in a result of FVA did not lose its commodity form.

The main purpose of FVA is to identify and prevent unnecessary costs due to elimination of unnecessary components, parts; simplification of product designs, materials substitution and more.

Principles of FVA - creative innovative thinking, consistency, complexity, functionality of objects' analysis and cost on their implementation, experience and knowledge of workers.

The main tasks of FVA are presented on Fig. 8.

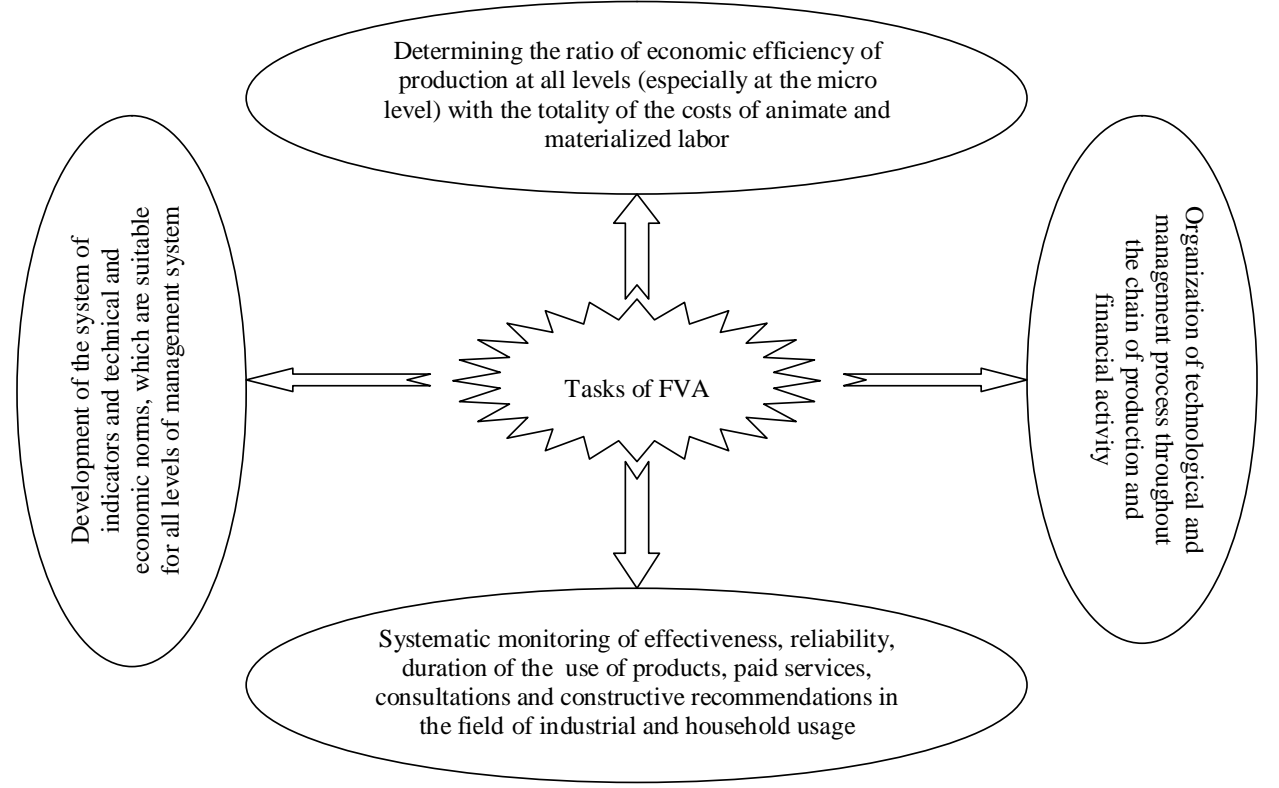

Fig. 8. The main tasks of FVA 
Skybinska Z., Gryniv T.

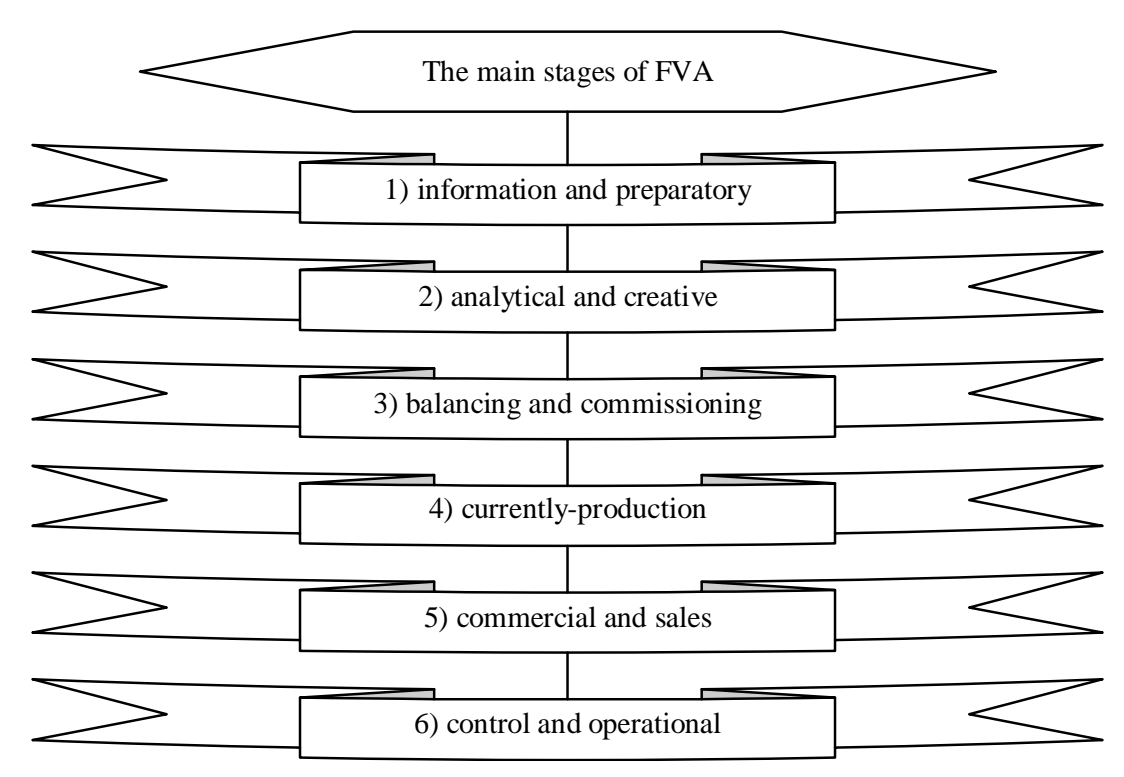

Fig. 9. The main stages of FVA

To select the correct version of the solution use methods: "Delphi", PATTERN and their modifications (expert survey). Essence of a method "Delphi" is that expert assessments foresee mutual analysis of the views of various experts in the absence of direct contact between them and anonymity. Method Pattern is that researched problem is divided into a number of sub problems, specific tasks and items subject to expert evaluation, then they are arranged in a "decision tree", determine coefficients of importance of each task, each element; estimates were put forward by experts are subject an open discussion. The disadvantage is the lack of clarity in building a "decision tree", lack of clarity in the selection of experts.

The main stages of FVA are shown on Fig. 9.

The first stage (information and preparatory) begins with the selection of the object. This could be the creation of fundamentally new product of industrial or a household purpose or radical reconstruction of pre-existing one. Labor capacity in this case is the scientific research work. New object must meet certain criteria that make it ideal not only for now but for the future. An important criterion is a reduction of material capacity. Required also a choice of biologically clean technology. The quality of the new product needs to be protected by patents, licenses and so on. The group of developers includes economists, analysts, financiers and accountants.

The second stage (analytical and creative) provides a comprehensive constructive weighing of the idea, puts forward a large number of alternative ideas, conducts their thorough theoretical consideration - assessing all the "pros" and "cons". Condition of this stage implementation is multiversion of ideas.

A list of works carried out at this stage:

- formation of all possible functions of the object of analysis and its components;

- classification and grouping of functions, identifying major, main, supporting, unnecessary functions of researched system and its components;

- construction of a functional model of the object;

- analysis and evaluation of the significance of functions;

- the construction of functional and structural model of the object;

- analysis and evaluation of costs associated with the implementation of the identified functions;

- comparative analysis of features' significance and costs of their implementation to identify areas with unreasonably high costs;

- carrying out a differentiated analysis for each of the functional area of reserves' concentration of economy labor and material costs;

- search for new ideas and alternatives of more cost effective solutions;

- creative discussion of recommendations, proposals, opinions of independent experts selected for the method of "Delphi", Pattern, etc .;

- preliminary elaboration of proposals formed by the creative team, their general systematization and by functions; 
- analysis and formation of variants of practical object's implementation (product design, technology, etc.);

- registration of materials related to the realization of creative and analytical stage.

The third stage (balancing and commissioning) is associated with experimentation, bench verification of fundamentally new product. After identifying deficiencies including essential is possible to complete or partially repeat the 2 nd stage.

At the fourth stage (currently-production) carry out an economic analysis of output, gross output, product and sales, analysis of products by the assortment (with the release of new models), product cost analysis, profitability in general and by type of products. At this stage, the analyst should clearly follow the identification of deficiencies and deviations from the standards set by the technological requirements and standards and must fix them strictly. Sometimes deficiencies are so essential that the new design is back for revision.

Fifth stage is commercial and sales. If all the products are manufactured by the enterprise, all the commissioning and balancing as well as currentlyproduction processes are under the direct control. If all the products are released by the union, concern, corporation, etc., production control is necessary and more difficult. A large number of people involved in the discussion of "behavior" of new products and further analysis, at the results of which are formed the appropriate conclusions and recommendations about the revision.

Sixth stage (operational and control). Required reverse contact with the consumer, because the consumer of industrial products is the true connoisseur of reliability, durability, quality of products produced, so collection of necessary information, summarizing mass consumer opinions become sometimes more important than the conclusion of the most qualified expert.

Thus, the FVA is an effective tool of search reserves to reduce costs, based on cheaper ways of implementation of core functions while eliminating unnecessary.

7) Fundamental analysis - a comprehensive study of thorough nature of phenomena under study using mathematical tools and other complex tools.

8) Situation analysis is intended to solve specific management problems in terms of the changed situation (economic, legal, political, etc.). It requires the implementation of systematic analytical study that would allow a comprehensive assessment of the situation and the consequences of decisions which was accepted, the ability to generate and analyze alternatives under uncertainty.

\section{Conclusion}

Consequently, there are many types of economic analysis, but in practice individual species in pure form are rare. At each level of management, a host of decisions are taken daily, which are supported by various types of economic analysis. The basis for making decisions on the regulation of production is operational analysis, which is characterized by the use of standard solutions. Operational analysis is used at all levels of management, but its share in the total volume of managerial decisions increases as we approach it directly to production.

For higher levels of managerial hierarchy characterized by strategic management, associated with planning and forecasting. As a rule, a comprehensive integrated economic analysis of individual associations and enterprises, a comprehensive analysis of the economic outlook for their development is used to solve strategic management tasks.

None of the specific types of economic analysis can exist without the other. Internal analysis is closely interwoven with the external, because the company can not exist within itself without maintaining the connection with the external environment: consumers, suppliers, financial institutions, insurance companies, etc. Perspective analysis can not be conducted without a retrospective analysis. Since the projected values of the activities of enterprises are always based on the analysis of indicators of past years.

The into branch analysis is closely linked to among branch, since the activities of the enterprise largely depends on the influence of external factors. But common in all types of economic analysis is that they all need timely, sufficient, complete, truthful and reliable information support.

\section{References}

1. Vashchenko L. O. Information and methodological support for analysis of the financial condition of enterprises: the dissertation author's abstract of the candidate of economic sciences: 08.06.04 / L. O. Vashchenko; State Academy of Statistics, 


\section{Skybinska Z., Gryniv T.}

Accounting and Auditing of the State Statistics Committee of Ukraine. - K., 2005. - 20 p.

2. Golovko T. V. Strategic analysis: Educational and methodical manual for independent study of discipline / By edition M. V. Kuzhelnogo / T. V. Golovko, S. V. Sagova. - K.: KNEU, 2002. - 198 p.

3. Zholonskyj E. Financial and economic analysis of business of industrial companies / E. ZholonskyjH.: Faktor, 2007. - 320 p.

4. Kindratska G.I . Economic analysis: Textbook / By edition prof. A. G. Zagorodnij / G. I. Kindratska, M. S. Bilyk, A. G. Zagorodnij. - 3-th edition, processed and supplemented-K.: Znannya, 2008. - 487 p.

5. Kindratska G. I. Structuring the economic analysis of the enterprise: management approach / G. I. Kindratska, A. G. Zagorodni, M. S. Bilyk // Bulletin of National University "Lviv Polytechnic". Series: Management and Entrepreneurship in Ukraine: Stages of Development and Development Issues. - 2007. - № 606. - P. 466-472.

6. Complex economic analysis of the enterprise / By edition N. V. Vojtolovskyj, A. P. Kalinina, I. I. Mazurova. - SPb.: Piter, 2010. - 576 p.
7. Korinko M. D. Control and analysis of business entities in the conditions of its differentiation: theory, methodology, organization: monograph / M. D. Korinko. - K.: IVC State Committee of Statistics of Ukraine, 2007. - 429 p.

8. Kupalova G. I. Theory of economic analysis: Tutorial / Kupalova G. I. - K.: Znannya, 2008. - 639 p.

9. Popovych P. Y. Economic analysis of business entities /P. Y. Popovych - K.: Znannya, 2008. - 630 p.

10. Problems and Prospects for the Development of Statistics, Audit and Economic Analysis: Collective Monograph / By edition V. A. Derij. - Ternopil: Krok, 2016. - 362 p.

11. Suharev P. M. System approach to the definition of the essence of the financial potential of the enterprise / P. M. Suharev, O. O. Batlukova // Trade and Market of Ukraine: Thematic collection of scientific works. - Donetsk: DonDUET, 2005. Publication 19, Part 2. - P. 110-115.

12. Sheremet A. D. Complex analysis of economic activity / A. D. Sheremet. - M.: INFRA-M, 2006. $415 p$. 